\title{
Intercostal artery reimplantation with saphenous vein during thoracoabdominal aortic replacement
}

\author{
Ibrahim Sultan, MD, Keith Dufendach, MD, Arturo Cardounel, MD, PhD, Forozan Navid, MD, and \\ Thomas G. Gleason, MD, Pittsburgh, Pa
}

\author{
Disclosures: Authors have nothing to disclose with regard to commercial support. \\ available ahead of print Dec 14, 2017. \\ PA 15232 (E-mail: sultani@upmc.edu). \\ J Thorac Cardiovasc Surg 2018;155:1963-5 \\ $0022-5223 / \$ 36.00$ \\ Copyright (C) 2017 by The American Association for Thoracic Surgery \\ https://doi.org/10.1016/j.jtcvs.2017.11.028
}

From the Department of Cardiothoracic Surgery, University of Pittsburgh Medical Center, Pittsburgh, Pa.

Received for publication Sept 3, 2017; revisions received Oct 23, 2017; accepted for publication Nov 12, 2017;

Address for reprints: Ibrahim Sultan, MD, Division of Cardiac Surgery, 5200 Centre Ave, Suite 715, Pittsburgh,

(4) Supplemental material is available online.

$\square$ Video clip is available online.

Spinal cord injury leading to permanent paralysis continues to be a morbid complication of open thoracoabdominal aortic aneurysm (TAAA) repair. Several strategies have been suggested for spinal cord protection during TAAA repair, including mild passive hypothermia, cerebrospinal fluid drainage, left heart bypass, and reimplantation of the intercostal arteries. ${ }^{1}$ Various techniques have been described for reimplantation of the intercostal arteries, with emphasis on improved graft patency, yet the optimal strategy for reimplantation is still unknown. ${ }^{1-3} \mathrm{We}$ describe the use of a reversed saphenous vein graft (SVG) for reimplantation of the intercostal arteries in a recent cohort of patients.

\section{MATERIALS AND METHODS}

Twenty-two consecutive patients underwent elective surgical replacement of the thoracoabdominal aorta for aneurysmal disease because of atherosclerotic aneurysms or chronic type B dissections. None of these patients had previously undergone open or endovascular aortic replacement (Table 1). All patients had a lumbar drain placed preoperatively. Neurocerebral monitoring was performed with electroencephalography and motor evoked potentials. The SVG was harvested with the patient in the supine position by means of an endoscopic approach that is commonly used for vein harvest for coronary artery bypass grafting. Next, the patient was placed in a modified lateral decubitus position for TAAA replacement. The TAAA was replaced in an open fashion, with left heart bypass and arch clamping or full cardiopulmonary bypass with deep hypothermic circulatory arrest, chosen primarily on the basis of the patient's arch anatomy. The proximal anastomosis was performed first, followed by the distal

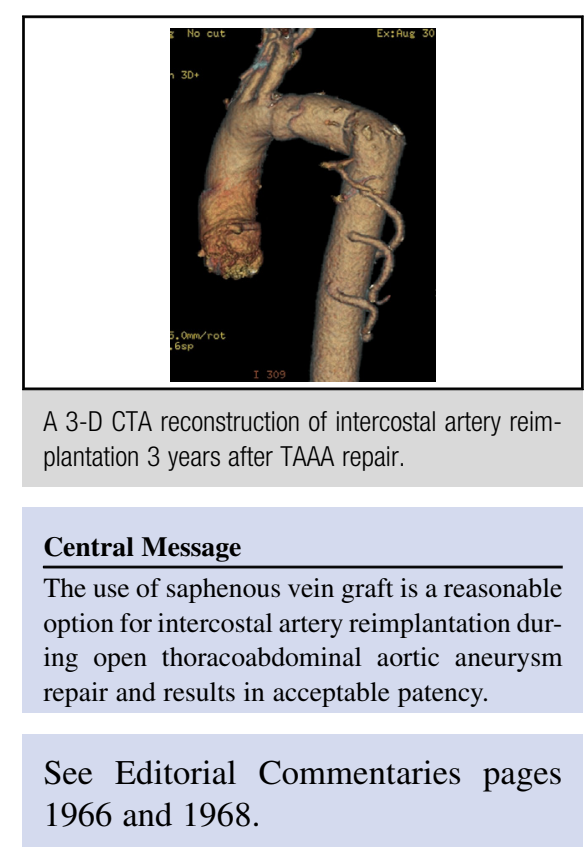

anastomosis (Video 1). Visceral arteries were reimplanted individually when involved, followed by intercostal artery reimplantation. The intercostal arterial cuffs in the region between T8 and L2 were preserved, and 1 to 3 large vessels in those regions were identified while correlating with preoperative computed tomographic angiography and selected for reimplantation. ${ }^{4}$ When no vessel of an appropriate size was identified, spinal cord revascularization was not performed. The distal anastomosis was performed first, followed by proximal anastomosis on to the aortic graft while ensuring no kink. The endoscopic vein harvest was performed by the physician assistant and took approximately 15 to 20 minutes, although this was not specifically timed for every procedure. After the anastomoses were completed, a transit time flow probe was used to interrogate the grafts to ensure that they had flow greater than $20 \mathrm{~mL} / \mathrm{min}$ and a pulse index less than 5. Data were analyzed after retrospective chart review of all the patients. This was approved by our institutional review board.

\section{RESULTS}

Of the patients, $12(54.5 \%)$ had extent 2 aneurysms, and $13(59.1 \%)$ had undergone previous cardiovascular surgery. There were no intraoperative or in-hospital deaths. One patient had a delayed aorta-related death from a graft infection at 2 years. Two patients $(9.1 \%)$ required dialysis for postoperative renal failure. There were $2(9.1 \%)$ episodes of temporary paraparesis, which resolved with postoperative cerebrospinal fluid drainage. No patients had permanent paralysis. A mean of 2 intercostal vessels were reimplanted at the time of surgery. Follow-up 
TABLE 1. Baseline characteristics, intraoperative outcomes, and postoperative outcomes of patients undergoing intercostal artery reimplantation during open thoracoabdominal aortic aneurysm repair

\begin{tabular}{lc}
\hline \multicolumn{1}{c}{ No. of patients } & $\mathbf{2 2}$ \\
\hline Age $(\mathrm{y})$ & $54.9 \pm 19.4$ \\
Male & $12(54.5 \%)$ \\
\hline Body mass index $\left(\mathrm{kg} / \mathrm{m}^{2}\right)$ & $25.5 \pm 4.24$ \\
\hline Diabetes & $4(18.2 \%)$ \\
\hline Preoperative dialysis & $0(0.0 \%)$ \\
\hline Previous cerebrovascular accident & $2(9.1 \%)$ \\
\hline Smoking & $16(72.7 \%)$ \\
Chronic lung disease & $5(22.7 \%)$ \\
\hline Peripheral vascular disease & $17(77.3 \%)$ \\
\hline Previous cardiovascular intervention & $13(59.1 \%)$ \\
Ejection fraction & $57.3 \% \pm 7.65 \%$ \\
Extent of aneurysm & \\
1 & $8(36.4 \%)$ \\
2 & $12(54.5 \%)$ \\
3 & $2(9.1 \%)$ \\
\hline Reintubation & $6(27.3 \%)$ \\
In-hospital mortality & $0(0 \%)$ \\
\hline Reoperation for bleeding & $2(9.1 \%)$ \\
Temporary paraparesis & $2(9.1 \%)$ \\
\hline Permanent paralysis & $0(0.0 \%)$ \\
\hline Postoperative cerebrovascular accident & $3(13.6 \%)$ \\
\hline Postoperative renal failure & $2(9.1 \%)$ \\
\hline & $2(9.1 \%)$ \\
\hline Postoperative dialysis & $14.6 \pm 13.4$ \\
\hline
\end{tabular}

computed tomographic angiography at 1 year revealed a $72 \%$ patency of the reimplanted intercostal vessels with SVG (Table E1). There were no saphenectomy-related complications.

\section{DISCUSSION}

Spinal cord ischemia is a common problem after TAAA repair, with published rates approaching $10 \%$ in large series. ${ }^{1}$ Reimplantation of the intercostal arteries has been a useful strategy in preventing spinal cord ischemia for more than 2 decades, yet the technique for reimplanting these vessels is still debated. ${ }^{4-6}$ Some groups have reported clear benefit in spinal cord protection when reimplantation of intercostal arteries is performed, whereas other groups have suggested no such benefit in their experience. ${ }^{7}$ Here we have described a novel technique with the use of reversed SVG for reimplantation of

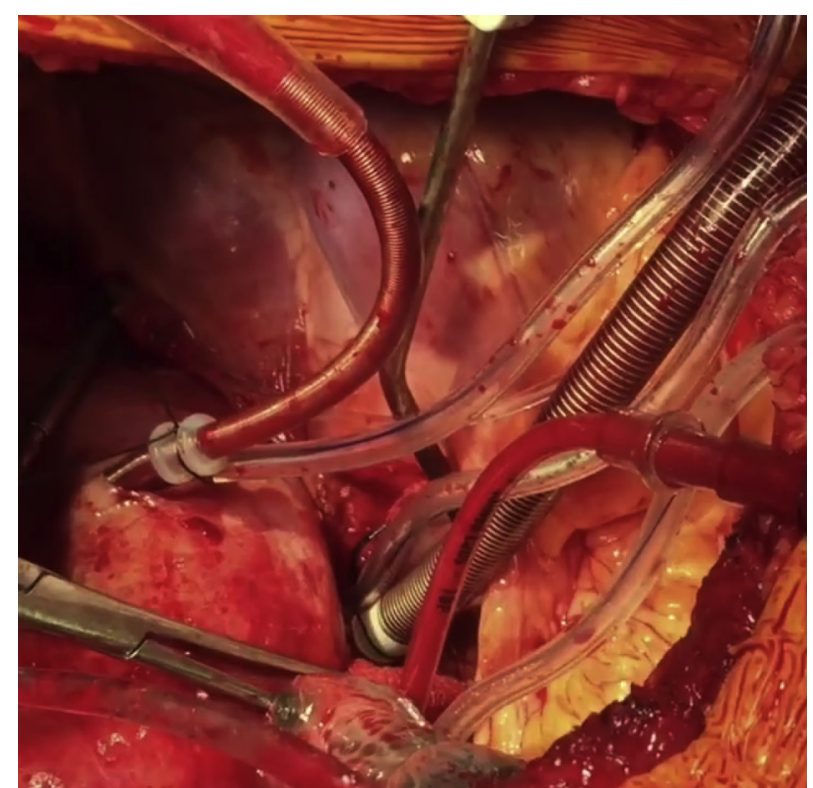

VIDEO 1. Brief video demonstration of extent 1 thoracoabdominal aortic aneurysm repair with reimplantation of intercostal arteries. IVC, Inferior vena cava; $E E G$, electroencephalography. Video available at: http://www. jtcvsonline.org/article/S0022-5223(17)32705-8/fulltext.

intercostal arteries during TAAA repair. An important preoperative and intraoperative consideration is selection of the vessels for implantation. A preoperative computed tomographic angiogram can be very useful, and selection is based on the location and size of existing intercostal arteries. We would not recommend the use of SVG as a conduit when it is of poor quality or when concomitant coronary artery bypass grafting needs to be performed, which would take precedence. A potential complication associated with this technique is potential saphenectomy-related complications. In our study, there were no cases of saphenectomy-related complications, indicating that this is a minor risk relative to the benefit of increased spinal perfusion and potential for increased patency with autologous transplanted vessels. The choice to use SVG rather than a prosthetic graft was based on the hypothesis of potential increase in patency. Although early results in our small cohort of patients are encouraging, long-term follow-up in a larger cohort will be important to determine patency of these grafts and their clinical impact.

\section{References}

1. Coselli JS, Lemaire SA, Preventza O, de la Cruz KI, Cooley DA, Price MD, et al. Outcomes of 3309 thoracoabdominal aortic aneurysm repairs. J Thorac Cardiovasc Surg. 2016;151:1323-37.

2. Murana G, Castrovinci S, Kloppenburg G, Yousif A, Kelder H, Schepens M, et al. Open thoracoabdominal aortic aneurysm repair in the modern era: results from a 20-year single-centre experience. Eur J Cardiothorac Surg. 2016;49:1374-81.

3. Coselli JS, De la Cruz KI, Preventza O, LeMaire SA, Weldon SA. Extent II thoracoabdominal aortic aneurysm repair: how I do it. Semin Thorac Cardiovasc Surg. 2016;28:221-37. 
4. Safi HJ, Miller CC III, Carr C, Iliopoulos DC, Dorsay DA, Baldwin JC. Importance of intercostal artery reattachment during thoracoabdominal aortic aneurysm repair. J Vasc Surg. 1988;27:58-66; discussion 66-8.

5. Zhang L, Sun XG, Yu CT, Chang Q, Qian XY. Intercostal artery reconstruction: the simple and effective technique on spinal cord protection during thoracoabdominal aortic replacement. Ann Vasc Surg. 2016;34:62-7.
6. Woo EY, Mcgarvey M, Jackson BM, Bavaria JE, Fairman RM, Pochettino A. Spina cord ischemia may be reduced via a novel technique of intercostal artery revascularization during open thoracoabdominal aneurysm repair. J Vasc Surg. 2007;46:421-6. 7. Wynn M, Acher C, Marks E, Acher CW. The effect of intercostal artery reimplan tation on spinal cord injury in thoracoabdominal aortic aneurysm surgery. $J$ Vasc Surg. 2016;64:289-96. 
TABLE E1. The number of intercostal arteries reimplanted in each patient

\begin{tabular}{|c|c|}
\hline Patient & $\begin{array}{l}\text { Intercostal arteries } \\
\text { reimplanted }\end{array}$ \\
\hline 1 & 2 \\
\hline 2 & 2 \\
\hline 3 & 2 \\
\hline 4 & 2 \\
\hline 5 & 1 \\
\hline 6 & 1 \\
\hline 7 & 3 \\
\hline 8 & 3 \\
\hline 9 & 2 \\
\hline 10 & 2 \\
\hline 11 & 2 \\
\hline 12 & 2 \\
\hline 13 & 2 \\
\hline 14 & 1 \\
\hline 15 & 0 \\
\hline 16 & 0 \\
\hline 17 & 2 \\
\hline 18 & 2 \\
\hline 19 & 1 \\
\hline 20 & 1 \\
\hline 21 & 2 \\
\hline 22 & 1 \\
\hline
\end{tabular}

